\title{
Significance of Big Data and Analytics in Higher Education
}

\author{
B.Tulasi \\ Assistant Professor \\ Department of Computer Science \\ Christ University \\ Bangalore,India
}

\begin{abstract}
The purpose and value of higher education is transforming. Technology is strengthening the capabilities of institutions to face the new challenges. Higher education has access to realms of data which can be used to improve decision making. The use of Big Data and analytics in higher education is relatively new area. The relevance of analytics is profoundly seen in many areas and higher education is no different. This paper examines the role of Big Data and analytics in higher education.
\end{abstract}

\section{General Terms}

Accountability, Heterogeneity,data.

\section{Keywords}

Analytics, Big Data, Learning Management Systems, Course Management Systems, Higher education, data mining.

\section{INTRODUCTION}

Impact of technology in higher education is very prominent. Technology has been strategically introduced into higher education to enhance different processes like teaching learning. When it is aligned with educational objectives and standards the impact is profound. The dynamics of higher education is changing and emphasizes the need to adapt rapidly. Higher education is under scrutiny from accrediting agencies, government and other stake holders to explore new means for improving and monitoring student success and other institutional policies.

Future education is more often connected with new technologies like ubiquitous computing devices, flexible class room design .But the most impounding aspect which is overlooked and which would revolutionize the field is "data". Higher education is a field where tremendous amounts of data are available. Analyzing this data would lead to realization of benefits of greater bound. Many institutions fail to make efficient use of the huge amount of data available.

The approach of using data and evidence to make decisions is transforming many fields. Data driven decisions have proven to improve business, organizational output and productivity [7].There is also an increased demand for making the organizational process transparent. All types of organizations share the need for associating themselves to analytics, to increase the efficiency and for greater accountability [2]. There is an increasing expectation from institutions to focus on reliable data for the processes like planning, resource utilization.
Capturing the data, storing in data warehouse and applying data mining concepts are the foundations for the future activities involved with higher education. Business intelligence which is part of today's corporate world when integrated into the education system would provide new and innovative solutions to the problems faced by the system. It would not be inappropriate to say that analytics would be integral part of future higher education.

With the advent of Internet, mobile devices there are huge amounts of data available which requires to be captured. According to McKinsey Global Institute amount of data in the world is exploding and analyzing this large data sets, called "Big Data" is key to success in this competitive era. Data has to be linked to other data to generate value to it. This can be effectively handled as the data is digital. The heterogeneity is a major problem associated with data. Most of the data available is not structured or is weakly structured which prevents the usage of the traditional tools to analyze it. . As existing database management techniques have their limitations in handling the volumes of data sets and heterogeneity of the data, new breed of technologies, databases and techniques have to be explored. Hadoop is a good example for it.

Big Data is the next frontier which will revolutionize higher education [1]. It would lead to a new wave of technological advances which would help increase academic effectiveness. The report of McKinsey points out that higher education is a weaker link among all the sectors of industry in data capture, IT intensity and data driven decision making. This is being overcome, by more number of educational institutions trying to capture and customize data. The data trail obtained through library usage, learning management systems social interactions like twitter is significant and is digital. These trails lead to valuable inputs regarding success of institutional processes [5]. Analysis of this data may lead to deeper understanding of the weaker sections in the processes.

\section{TAKE AWAYS FROM BIG DATA AND ANALYTICS}

Academic analytics will be an essential component of future. It encapsulates all the activities in higher education affecting administration, research, resource allocation and management. Adaptation to analytics would lead the institution to be more intentional, intelligent with data and evidence. Big data and analytics add greater value to higher education.

- They can improve decision making and resource management.

- Success rate of students can be increased by identifying the risk at earlier stage. 
- Institutional growth can be enhanced and challenges tackled effectively by the transparent data available.

- Innovative models can be developed for transforming the university or college system.

- Decision making would be facilitated by "what if" experiments.

- Usage of social networking and technical and information network could provide assistance in handling complex issues.

- Hard values like patents and soft values like brand building generated by faculty activity can be determined.

- Productivity of the institution can be enhanced through effective responses generated due to real time data availability.

\section{PHASES FOR ANALYSING BIG DATA}

The benefits of Big Data and analytics are significant and can be seen in projects like "Sloan Digital Sky Survey" [11]. Though success has been achieved it is not to the fullest, there are some technical challenges which need to be tackled. The size of data, the heterogeneity and the speed of data are the major challenges associated with Big Data.

Different phases involved for analytics as identified by Campbell and Oblinger (2007) are Capture, Report, Predict, Act and Refine. Big Data is obtained from different data generating resources. Considering the nature of Big Data the major steps involved in analyzing Big Data can be given as Acquisition, Extraction, Integration, Analysis or modeling and interpretation. The below figure depicts the various phases.

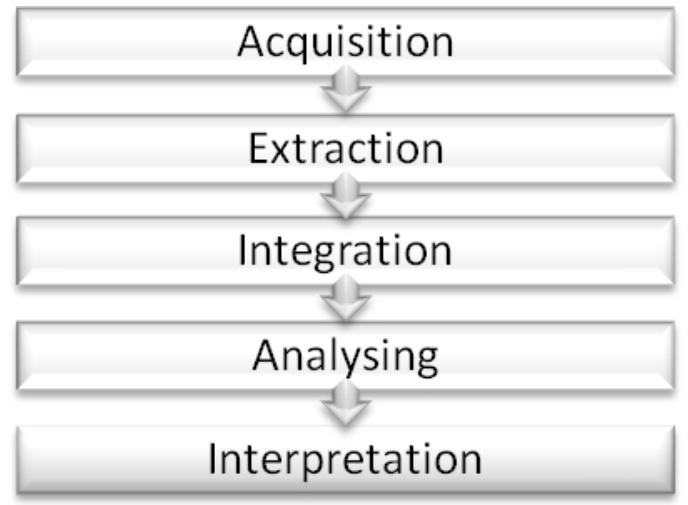

Figure 1 Phases of Big Data Analysis

\subsection{Acquisition and Extraction of data}

Data may be taken in real time from social networking sites (like Facebook, Twitter, Blogs) Course Management systems (CMS), Learning Management System (LMS) and physical world data like library usage. Data generated by these sources would be voluminous and of peta bytes order. Identifying the data of interest in this huge volume is an important task. This can be done by defining filters which would discard unwanted data and retain only useful information.

Generation of right metadata to describe about the data recorded is an essential task. Recording data at the initial stage might not be advantages unless the information which can be interpreted from it can be used till the last phase of data analysis. Hence it becomes providential to generate suitable Meta data and data systems.

Information collected has to be formatted for it to be ready for analysis. For example, the records from a library or any social network are not in a format which can be utilized directly. Information extraction has to be done to get the required information from the data sources and represent it in a suitable structural format for analysis. This is a major technical challenge.

\subsection{Integration and Analysis}

Considering the volume of data and heterogeneity of it data analysis is more challenging .For an effective outcome the process of locating, identifying, and understanding and citing a data has to be completely automated. Data integration plays a pivotal role with the differences in data structure and semantics being expressed in a form that is computer understandable.

Query processing Big Data would be different from the traditional approach as the data is heterogeneous, noisy and dynamic. Though the data is noisy there might be critical data which can be obtained. Information redundancy exists through interconnected Big Data which helps in solving the problems of missing data, checking conflicting cases and identification of hidden relationships. The lack of coordination between database systems with analytical packages that perform nonSQL processing like data mining is the impending issue associated with Big Data.

\subsection{Interpretation}

Analyzing Big Data would have less value if the results are not properly interpreted by decision maker or user. The interpretation involves examining all assumptions made and retracing of the analysis. This process would be tedious because of the complexity involved with Big Data. Hence the necessity to provide supplementary information along with the results is quite essential.

\section{PLANNING AND IMPLEMENTATION}

The use of Big Data and analytics in higher education is relatively new practice. It is also one of the future areas of research. The Horizon reports of 2011 and 2012 [9] indicate the inclusion of analytics in higher education in span of three to five years.

Analytics projects to be successful in an institution would require data, technology, statistical requirements and above all skill and leadership. Any effort for planning and implementation of an analytics project in an institution would require leaders committed to decision making based on the institutional data. The role to be played by analytics relies on the institutions vision of the next generation learning system.

To adapt analytics an institution should 
- Identify leaders who can use data to solve complex issues.

- Identify the key values on which data can be measured,

- Identify tools and models suitable to their requirements.

- Embed analytics in institutional process.

- Instill a plan for effective communication.

\section{THE FUTURE}

Big Data and Analytics in higher education can be transformative, altering the existing processes of administration, teaching, learning, academic work.[3] When analytics is applied the traditional view of courses would be changed leading to a network of relations between knowledge and skills. Knowledge domains are mapped and a student can be evaluated with help of the maps.

Analytics would lead to innovation in education, which can be of two types sustainable and disruptive [6].Sustainable innovation would improve the existing system and processes. Disruptive innovation would be new ideas, activities which require change in behavior or processes. Innovation of this kind would remove the current practice and create a new system. In any institution both forms of innovation are required to adapt to the growing needs in higher education.

\section{CONCLUSION}

Big Data and Analytics have undoubtedly a significant role to play in future of higher education. The increasing involvement of analytics in business and government sectors affirm the same. The value of analytics and Big Data in higher education is in reform activities and improving teaching, learning process. Linda Baer and John Campbell mention the need for Educational Positioning System (EPS), which would furnish students with navigational tools for their educational journey [3]. As Alan Kay quotes "The best way to predict future is to invent it", to meet the demands of improved productivity higher education has to bring the tool of analytics into the system. [10].

\section{REFERENCES}

[1] Big Data:The next frontier for innovation, competition and productivity.James Maniyka, Executive summary ,McKinsey Global Institute ,May 2011, <http://www.mckinsey.com/mgi/publication/big.data/M GI_big_data_exec_summary.pdf $>$.

[2] IBM,"Real World Predcitive Analysis:Putting Analysis into Action for Visible Results",2010,http://public.dhe.ibm.com/common/ssi/ec m/en/ytw03112usen/yt03112USEN.PDF.

[3] Game Changers, Chapter 4 Linda Baer and John Campbell, EDUCAUSE publications May 2011 Tavel, P. 2007 Modeling and Simulation Design. AK Peters Ltd.

[4] Penetrating the fog: Analytics in learning and education, Phil Long and Gorge Siemens, EDUCAUSE Review vol 46,no 5 September/October 2011.

[5] John P.Campbell and Diana G. Oblinger "AcademicAnlaytics:A new tool for a new era",EDUCAUSEReview(July/August2007)4157,http"//net.educause.edu/ir/library/pdf/erm0742.pdf

[6] John P.Campbell and Diana G. Oblinger ,"Academic Anlaytics EDUCAUSE white paper,2007,http://net.educause.edu/ir/library/pdf/PUB60 101.pdf

[7] H.J.Watson,"Business Analytics Insight : Hype or Here to stay?" Buisness Intelligence Journal,16(1),2011,4-8.

[8] Learning analytics as a tool for closing the assessment loop in higher education,Karen D. Mattingly,Marget C.Rice,Zane.L Berge,Journla of Knowledge management and E-Learning Vol4 No.3.

[9] Johnson, L., Smith, R., Willis, H., Levine, A., and Haywood, K., (2011). The 2011 Horizon Report.Austin, Texas: The New Media Consortium

[10] Predicting Future by Alan. C.Kay, http://www.ecotopia.com/webpress/futures.htm

[11] Data Access for SDSS DR9 http://www.sdss3.org/dr9/data_access 